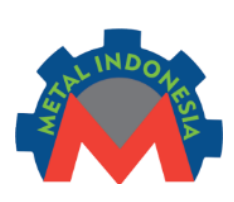

JMI Vol. 39 No. 1 Juni 2017

METAL INDONESIA

Journal homepage:

http://www.jurnalmetal.or.id/index.php/jmi

p-issn : $0126-3463$

e-issn : $2548-673 \mathrm{X}$

\title{
OPTIMASI SISTEM PEMBERSIHAN JAGUNG PADA MESIN PEMANEN JAGUNG KOMBINASI
}

\section{CORN CLEANING SYSTEM OPTIMATION OF CORN COMBINE HARVESTER}

\author{
Sina Jamilah, Trismiyati, Haruman Wiranegara, Hafid \\ Balai Besar Logam dan Mesin \\ Kementerian Perindustrian \\ Jl. Sangkuriang 12 Bandung - Jawa Barat \\ email: sina-jamilah@kemenperin.go.id
}

\begin{abstract}
Abstrak
Dalam penelitian ini, mesin pemanen kombinasi untuk padi dimodifikasi untuk memanen jagung. Agar jagung dapat dipanen dengan mesin tersebut maka diperlukan penyesuaian pada beberapa bagian, salah satunya sistem pembersihan pada mesin pemanen kombinasi. Hal ini disebabkan oleh perbedaan lahan, pohon dan buah dari padi dan jagung. Penelitian ini bertujuan untuk meningkatkan kebersihan bulir jagung yang telah terpipil dan membuang sampah yang masuk ke dalam ruang penyaringan sehingga diperoleh pembersihan yang optimal serta mengurangi jagung yang terbuang. Metode penelitian menggunakan rekayasa mundur dengan mengidentifikasi fungsi dari bagian-bagian sistem pembersihan mesin pemanen kombinasi. Pengujian dilakukan di laboratorium dengan kondisi lantai rata dan datar. Pengujian meliputi kadar air jagung, bentuk dan posisi pengayak, lebar celah pembuangan, kemiringan penampung jagung, serta pengaruh putaran mesindan kecepatan angin dari peniup. Hasil pengujian menunjukkan bahwa kadar air jagung 19\% menghasilkan jagung pipilan yang bersih. Agar biji jagung dapat bergerak ke area screw pembawa, perlu kemiringan penampung jagung minimal sebesar $20^{\circ}$. Celah pembuangan sampah dibuat sebesar $65 \mathrm{~mm}$ supaya sampah tidak tersumbat pada saat pembersihan butir jagung. Posisi dan bentuk pengayak juga berpengaruh terhadap jumlah jagung yang terbuang dan proses penyaringan. Pengayak yang dipasang dengan kemiringan $20^{\circ}$ berhasil mengurangi jagung yang terbuang menjadi $4,67 \%$ pada putaran mesin $1500,2 \mathrm{rpm}$ dan kecepatan angin dari peniup sebesar $1,7-3,9 \mathrm{~m} / \mathrm{s}$. Dari hasil pengujian tersebut, sampah yang masuk ke ruang penyaringan dapat dikeluarkan dengan baik sehingga jagung hasil pipilan bersih dari pengotornya.
\end{abstract}

Kata kunci: sistem pembersihan jagung, modifikasi pengayak, mesin pemanen jagung, parameter pembersihan jagung

\begin{abstract}
In this research, combined rice harvester machine is modified for harvesting corn. In order to enable the corn can be harvested by that machine, it is necessary to adjust some parts, one of which was the combined harvester cleaning system. This is due to several differences between rice and maize in land, trees, and grains. Research objective is to improve cleanliness of corn grains that have been threshed and remove waste that goes into the screening room in order to obtain optimal cleaning also to reduce wasted corn grains. The research method uses reverse engineering by identifying the function of the cleaning system parts of the combine harvesting machine. Tests conducted in the laboratory with a flat floor. Tests include corn moisture content, shape and position of the sieve, widegap discharge, the slope of the corn container, as well as the influence of the engine speed and the wind speed of the blower. The test results showed that the corn moisture content of 19\% produces clean corn grain. In order for corn grain move to an area of the carrier screw, minimum tilt of the corn container is $20^{\circ}$. Sewage gap is made of $65 \mathrm{~mm}$ so that the garbage is not clogged at the time of cleaning the grains of corn. The position and shape of the sieve also affects the losses of corn grain and the sieveing process. Sieve mounted with a slope of $20^{\circ}$ successfully reduce the losses of corn grain to $4.67 \%$ at engine speed of $1500.2 \mathrm{rpm}$ and the blower wind speed of 1.7 to $3.9 \mathrm{~m} / \mathrm{s}$. From the
\end{abstract}


test results, the waste that goes into the filtration room can be removed so well that the shelled corn is clean from the impurities.

Key words: corn cleaning system, sieve modification, combine corn harvester, corn cleaning parameter

\section{PENDAHULUAN}

Saat ini di Indonesia telah diproduksi mesin pemanen padi kombinasi. Petani sudah memanfaatkan mesin tersebut untuk mempermudah dan mempercepat panen padi. Namun untuk memanen jagung, belum ada mesin pemanen kombinasi yang diproduksi di Indonesia. Oleh karena itu, pada penelitian ini mesin pemanen kombinasi untuk padi dimodifikasi untuk memanen jagung.

Proses pemanenan menggunakan mesin pemanen kombinasi ini dimulai dengan memotong tanaman, kemudian tanaman tersebut ditarik dan masuk ke bagian pemipil (thresher). Hasil pipilan diarahkan ke bagian pengayak (sieve) untuk memisahkan butiran dengan pengotornya. Selain itu, pemisahan pengotor juga dilakukan dengan blower. Pengotor ini berasal dari tanaman yang ikut terpotong pada saat proses pemipilan. Butiran yang telah dibersihkan dari pengotornya dibawa oleh screw pembawa ke bagian penampung yang kemudian butiran tersebut dapat langsung dikemas dalam karung. Agar jagung bisa dipanen dengan mesin tersebut maka diperlukan penyesuaian pada beberapa bagian, salah satunya sistem pembersihan mesin pemanen kombinasi.

Sistem pembersih dalam mesin pemanen jagung kombinasi merupakan salah satu bagian yang mempengaruhi unjuk kerja mesin keseluruhan. Performa lapisan penyaring dipengaruhi oleh faktor desain, kondisi operasi dan sifat tanaman. Kecepatan pengumpan, kipas, dan pembukaan chaffer adalah faktor operasi yang banyak mempengaruhi performa unit pembersih mesin pemanen kombinasi (Mirzazadeh, Abdollahpor, \& Vahed, 2015).

Persentase kerusakan biji jagung oleh serangga linear dengan penurunan kelembaban biji semua hibrida pada dua periode evaluasi. Kadar air biji jagung dalam rentang 22-26\% (w.b.) merupakan kondisi kadar air biji jagung terbaik untuk dipanen(Marques et al. 2008).
Berdasarkan SNI 7428:2008 mengenai mesin pemipil jagung - unjuk kerja dan cara uji, kondisi bahan uji biji jagung memiliki kadar air rata-rata $18-20 \%$. Syarat unjuk kerja standar efisiensi minimumnya adalah $95 \%$ dan jumlah jagung terbuang maksimum 5\% (Badan Standardisasi Nasional 2008).

Pada kondisi yang telah dipelajari, hasil optimal untuk pengujian adalah dengan menggunakan jagung yang telah dipanen pada kandungan air $25 \%$ atau kurang dan dikeringkan pada temperatur udara dari $82^{\circ} \mathrm{C}$ atau lebih rendah (Peplinski, Anderson, and Brekke 1982).

Pengukuran kadar air dilakukan dengan cara biji jagung dipanaskan di oven sampai $103 \pm$ $1^{\circ} \mathrm{C}$ selama 72 jam (Marques et al. 2008).

Kadar air jagung secara langsung mempengaruhi kualitas dan waktu penyimpanan. Dengan menggunakan metode thefour-elektroda dengan Agilent E4980A presisi LCR meter, spektroskopi impedansi listrik dari jagung manis dan jagung lilin diperoleh kadar air yang berbeda (Pengfei et al. 2015).

Hasil dari pemanenan dan jumlah kehilangan biji menunjukkan bahwa header konvensional dimana gaya vertikal diberikan untuk memisahkan batang, menghasilkan kerusakan yang terjadi pada tanaman dan jumlah kehilangan biji menjadi terlalu besar. Hasil dari penelitian menunjukkan bahwa hal-hal yang berpengaruh terdapat pada cutter bar, perlu adanya modifikasi pada header yang dibuat di Iran untuk mengurangi jumlah kehilangan biji. Pemilihan material juga perlu diperhatikan untuk konstruksi header, cutter bar, straw walker, rantai penarik dan poros sehingga mengurangi jumlah kerugian pada header. Sebelum memulai pemanenan, perlu dilakukan pengukuran kadar air jagung, memastikan putaran header dan concave sudah benar, dan mengatur ruang antara header dan concave 
untuk mengurangi jumlah kehilangan biji. (Mohammad, Aziz, and Amini 2014).

Performa mesin pemipil jagung tergantung pada kadar air biji jagung, kecepatan pengumpannya dan kecepatan blade (Darudkar 2015).

Dalam sistem pembersihan, biji dipisahkan dari tumpukan material yang dihasilkan dari pemipil dan walker. Proses pemisahan berlangsung pada sieve dari sistem pembersihan berkat gerakan osilasi dari sieve dan aliran udara yang menyapu lapisan pengotor (Voicu, Casandroiu, and Tarcolea 2008).

Penelitian ini bertujuan untuk meningkatkan kebersihan bulir jagung yang telah terpipil dan membuang sampah yang masuk ke dalam ruang penyaringan sehingga diperoleh pembersihan yang optimal serta mengurangi jagung yang terbuang.

Manfaat dari penelitian ini adalah untuk meningkatkan kebersihan hasil panen jagung.

\section{METODOLOGI}

Penelitian ini dilakukan pada tahun 2016 di Balai Besar Logam dan Mesin - Bandung, Jawa Barat.

Metode yang digunakan adalah reverse engineering (rekayasa mundur). Identifikasi fungsi dilakukan pada bagian-bagian sistem pembersihan mesin pemanen kombinasi.

Tahapan penelitian ini dapat dilihat pada Gambar 1 di bawah ini.

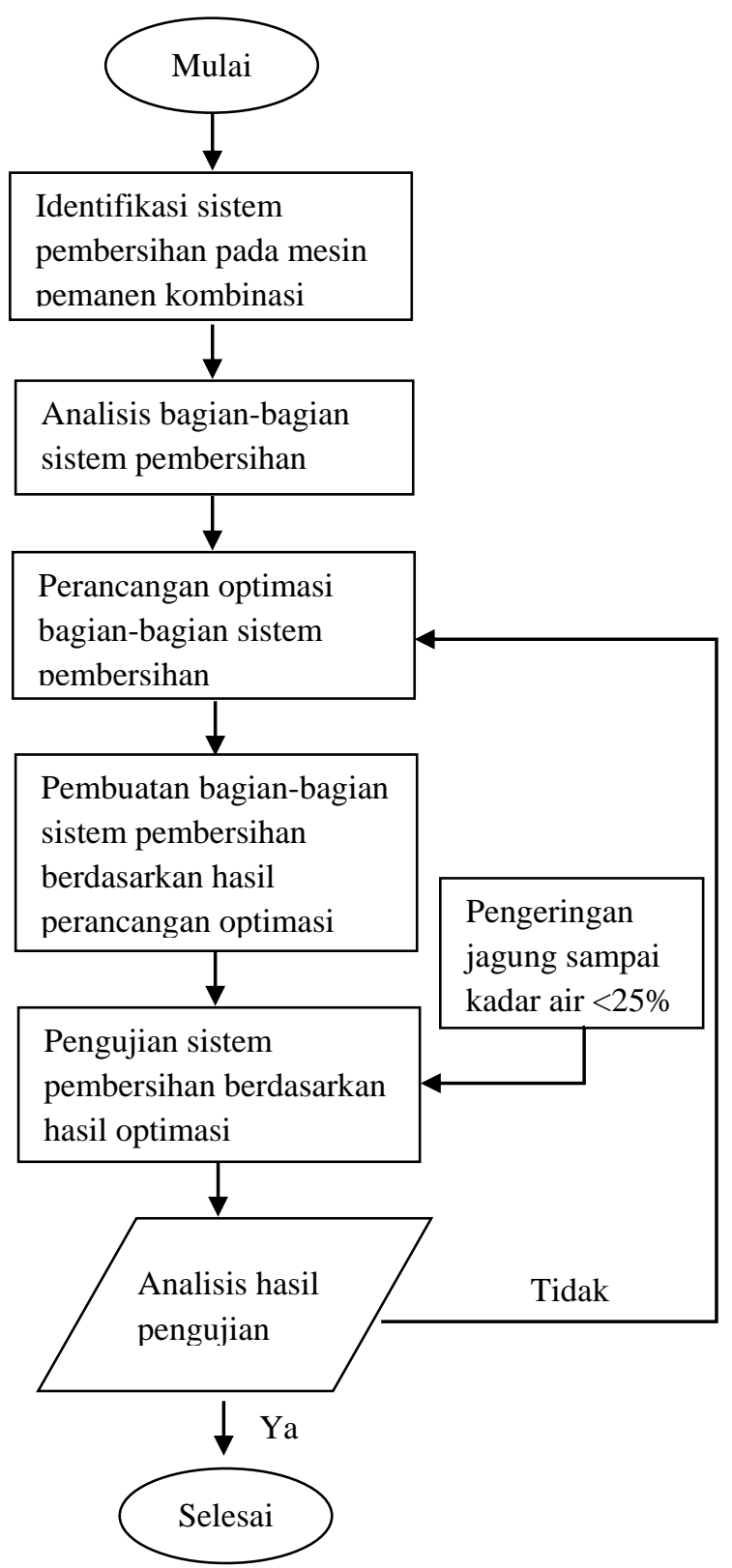

Gambar 1. Diagram blok tahapan optimasi sistem penyaring jagung pada mesin pemanen jagung kombinasi

Identifikasi sistem pembersihan pada mesin pemanen jagung dilakukan dengan mempelajari bagian-bagian dari mesin tersebut.

Penelitian dilakukan pada mesin pemanen padi kombinasi merk HORNET CCH-7130 yang dimodifikasi untuk memanen jagung dengan bahan pohon jagung hasil panen.

Bagian-bagian sistem pembersih dianalisis berdasarkan fungsinya. Hasil analisis tersebut dijadikan dasar untuk merancang bagian-bagian 
yang perlu diperbaiki untuk mengoptimumkan sistem pembersihan.

Proses pengerjaan menggunakan mesin potong, mesin las, mesin milling, dan mesin gerinda.

Bahan uji yang digunakan pada penelitian ini adalah pohon jagung.

Bahan untuk memodifikasi mesin adalah sebagai berikut plat stainless, plat stripe, plat perforated steel dan kawat las.

Alat ukur putaran mesin menggunakan tachometer Krisbow KW 06-563. Kecepatan angin diukur dengan anemometer SILVA ADC PRO.

Pohon jagung dengan jagungnya sebagai sampel uji dikeringkan di ruangan dengan udara terbuka. Setelah beberapa lama pengeringan dilakukan, jagung diambil untuk diukur kadar airnya. Kadar air jagung diukur dengan menggunakan Grain Moisture Meter JV-002S.

Pengujian dilakukan dalam skala laboratorium dengan cara mengumpan pohon jagung ke mesin pemanen kombinasi dengan cara manual.

Parameter proses yang dianalis pada saat pengujian sistem pembersihan mesin pemanen jagung kombinasi adalah kecepatan putar engine sebagai variabel bebas dan kecepatan angin pada blower sebagai variabel terikat. Kemudian dilakukan pengujian dengan mengubah-ubah bukaan blower untuk mengetahui posisi bukaan blower yang terbaik.

\section{HASIL DAN PEMBAHASAN}

\section{Sistem Pembersihan pada Mesin Pemanen Jagung Kombinasi}

Mesin pemanen jagung kombinasi memiliki sistem pembersihan dengan menggunakan blower dan sieve. Sieve berfungsi untuk memisahkan butir jagung dengan pengotornya, sedangkan blower berfungsi untuk membuang pengotor tersebut keluar dari mesin. Pada saat beroperasi, sieve bergerak naik-turun menyaring butir jagung dari pengotornya.

Tanpa mengubah blower, hal-hal yang berperan penting dalam sistem pembersihan ini adalah kemiringan penampung jagung, celah pembuangan sampah serta posisi dan bentuk sieve.

\section{Kadar Air Jagung}

Hasil panen dengan kadar air jagung > 30\% ditunjukkan pada Gambar 2. Jagung hasil panen menggunakan mesin pemanen jagung kombinasi masih bercampur dengan pengotornya dari kulit, batang dan bonggol jagung. Hal ini disebabkan oleh massa jenis pengotor menjadi lebih berat ketika kadar air semakin besar. Oleh karena itu, proses pembersihan menggunakan blower menjadi tidak optimal.

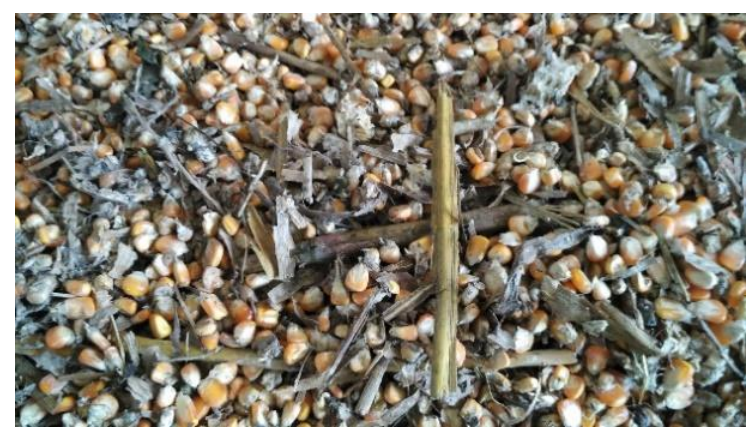

Gambar 2. Hasil proses pemanenan dengan kadar air jagung $>30 \%$

Kadar air jagung merupakan salah satu faktor yang dapat mempengaruhi kualitas hasil pipilan jagung baik dipipil secara manual maupun menggunakan mesin. Oleh karena itu, kadar air jagung merupakan salah satu persyaratan awal yang harus dipenuhi agar hasil pipilan tidak rusak dan bersih dari pengotornya.

Kadar air jagung pada saat dipanen untuk pemipilan jagung yang baik adalah $<25 \%$ agar jagung mudah dipipil dari bonggolnya, kualitas jagung pipilan bagus, dan sampah dapat dipisahkan dengan lebih mudah menggunakan blower.

Pohon jagung untuk pengujian dikeringkan di ruangan dengan udara terbuka. Pengukuran kadar air 4 sampel uji dilakukan masing masing 15 kali. Tabel hasil pengukuran ditunjukkan pada Tabel 1. 
Tabel 1. Tabel hasil pengukuran kadar air

\begin{tabular}{|c|c|}
\hline Sampel ke-n & $\begin{array}{c}\text { Nilai Rata-rata } \\
\text { Kadar Air (\%) }\end{array}$ \\
\hline 1 & 18,9 \\
\hline 2 & 19,0 \\
\hline 3 & 19,3 \\
\hline 4 & 18,9 \\
\hline $\begin{array}{c}\text { Kadar Air } \\
\text { rata-rata }\end{array}$ & 19,0 \\
\hline
\end{tabular}

Setiap perubahan yang dilakukan pada sistem pembersihan ini dilakukan pengujian menggunakan jagung yang kadar airnya telah mencapai $<25 \%$.

Penentuan kemiringan penampung jagung

Penampung jagung dengan kemiringan $<10^{\circ}$ tidak dapat menggerakkan jagung yang masuk ke arah screw pembawa. Oleh karena itu, jagung menumpuk di sekitar celah pembuangan pengotor. Sampah pengotor yang seharusnya terbuang menjadi terhambat.

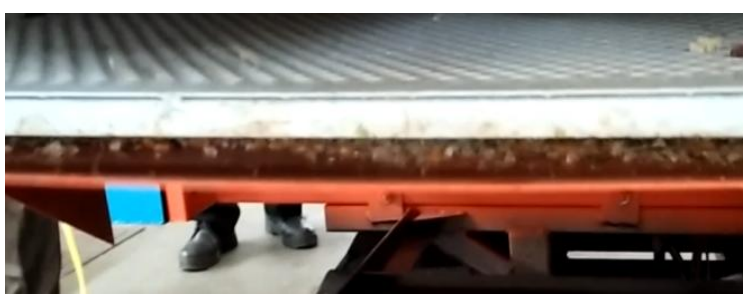

Gambar 3. Jagung tidak bergerak turun ke area screw pembawa

Untuk mengetahui kemiringan yang diperlukan agar jagung dapat bergerak (jatuh) ke area screw pembawa, dilakukan perhitungan dengan rumus sebagai berikut (Hibbeler 2011):

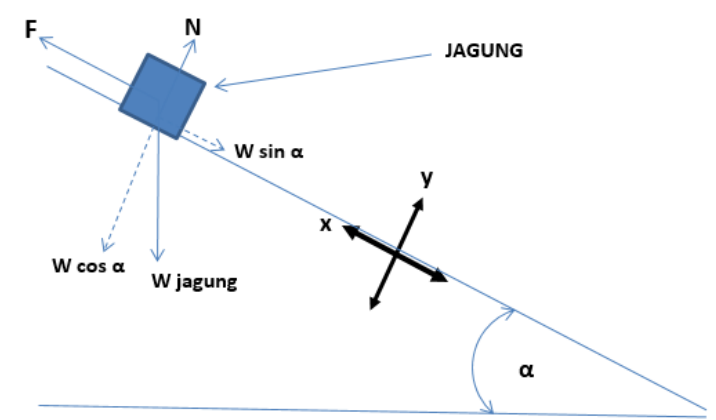

Gambar 4. Ilustrasi perhitungan sudut penampung jagung

$\sum f x=0$
$\sum f y=0$
Dimana:

$\sum \mathrm{fx}=$ jumlah gaya-gaya pada sumbu $\mathrm{x}$

$\sum f y=$ jumlah gaya-gaya pada sumbu $y$

Data yang digunakan adalah massa jenis jagung $721 \mathrm{~kg} / \mathrm{m}^{3}$ (Setyaji 2017) dan koefisien gesek antara jagung dan logam 0,37 (Direktorat Pembinaan Sekolah Kejuruan Menengah Kementerian Pendidikan dan Kebudayaan RI 2013). Dari hasil perhitungan, jagung akan mulai jatuh minimal pada sudut $\alpha>20^{\circ}$.

$\mathrm{F}=\mathrm{F}$ gesekan antar jagung $+\mathrm{F}$ gesekan jagung dan plat

$\sum$ fy $=0$

$\mathrm{N}-\mathrm{W} \cos \alpha=0$

$\mathrm{N}=\mathrm{W} \cos \alpha$

$\sum \mathrm{fx}=0$

$(\mathrm{N} . \mu 1+\mathrm{N} . \mu 2)-\mathrm{W} \sin \alpha=0$

$\mathrm{N}(\mu 1+\mu 2)=\mathrm{W} \sin \alpha$

Maka :

$\mathrm{W} \cos \alpha(\mu 1+\mu 2)-\mathrm{W} \sin \alpha=0$

$\mathrm{W} \cos \alpha(\mu 1+\mu 2)=\mathrm{W} \sin \alpha$

$\mathrm{W}(\mu 1+\mu 2) / \mathrm{W}=\sin \alpha /(\cos \alpha)$

$\mathrm{W}(\mu 1+\mu 2) / \mathrm{W}=\operatorname{tg} \propto$

$\propto=\operatorname{arctg}\{\mathrm{W}(\mu 1+\mu 2) / \mathrm{W}\}$

$\propto=\operatorname{arctg}\{(\mu 1+\mu 2)\}$

$\propto=\operatorname{arctg}\{(0.37)\}$

$\propto=20$ derajat

Pada pengujian akan diposisikan kemiringan $20^{\circ}-25^{\circ}$ untuk mengetahui seberapa besar pengaruhnya terhadap jagung yang masuk ke area penampung. Gambar 5 merupakan posisi variasi kemiringan pada penampung jagung hasil penyaringan. Gambar 6 dan Gambar 7 merupakan hasil pengujian pada kemiringan $20^{\circ}$ dan $25^{\circ}$.

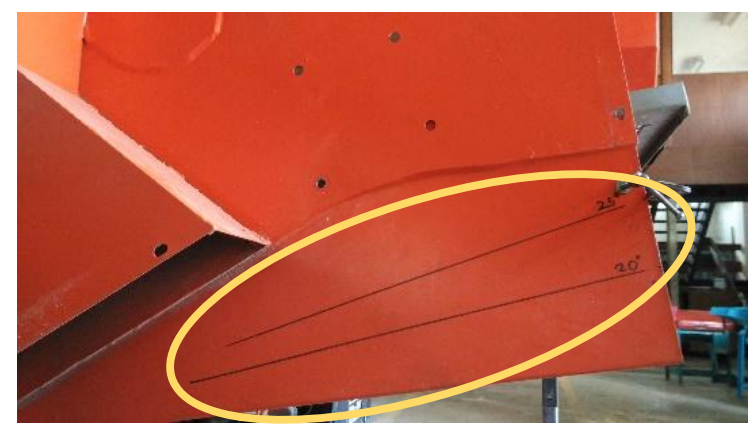

Gambar 5. Variasi kemiringan penampung jagung 


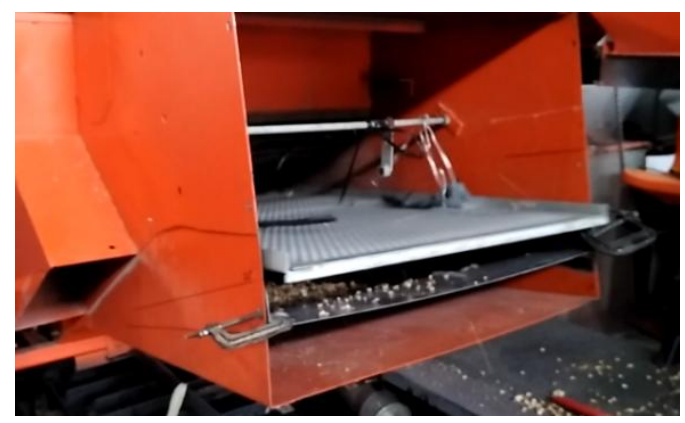

Gambar 6. Hasil pengujian pada kemiringan $20^{\circ}$

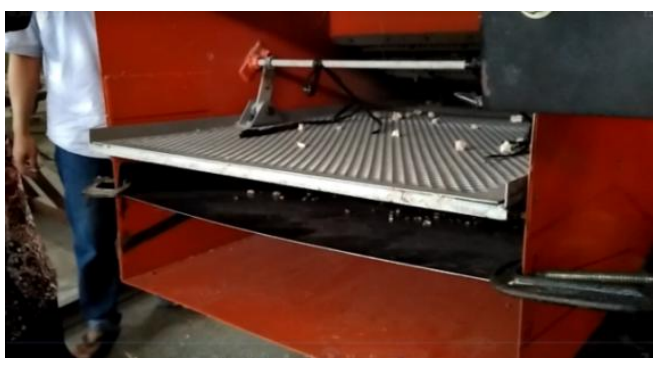

Gambar 7. Hasil pengujian pada kemiringan $25^{\circ}$

Pengujian ini menunjukkan hasil yang positif. Jagung yang masuk ke area penampung dapat bergerak turun ke area screw pembawa baik pada kemiringan $20^{\circ}$ maupun $25^{\circ}$. Pada Gambar 6 dan Gambar 7 terlihat jagung tidak menumpuk di area penampungan jagung. Semakin besar kemiringannya maka semakin cepat pula jagung bergerak ke area screw pembawa.

\section{Celah pembuangan sampah}

Sampah menumpuk di celah pembuangan dan tidak dapat keluar sehingga sampah dikeluarkan secara manual seperti terlihat pada Gambar 8.

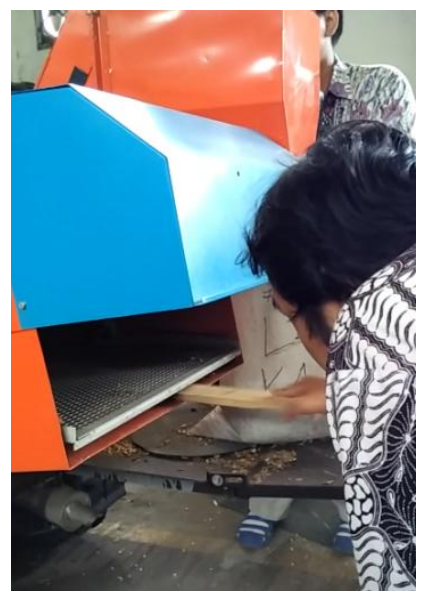

Gambar 8. Sieve sebelum perubahan
Ketika tanaman jagung dipanen pada kondisi $20 \%$ moisture content, dihasilkan $31,88 \%$ biji, $52,12 \%$ batang, $11,52 \%$ tongkol dan $4,48 \%$ kulit (Singh et al. 2015). Dengan demikian, total sampah yang dihasilkan adalah $68,15 \%$.

Menumpuknya sampah di celah pembuangan disebabkan oleh jumlah sampah yang masuk ke area penampung lebih banyak dibandingkan dengan jumlah sampah yang keluar dari area penampungan.

Berdasarkan hasil pengujian, celah pembuangan sebesar $30 \mathrm{~mm}$ tidak cukup untuk mengeluarkan sampah pengotor. Harus ada celah yang lebih besar untuk membuang sampah hasil pipilan. Gambar 9 menunjukkan celah pembuangan sampah yang telah diperbesar.

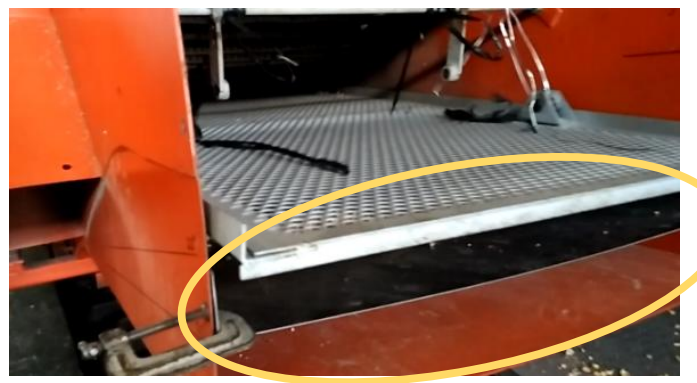

Gambar 9. Sieve setelah perubahan

Dengan memperbesar celah pembuangan menjadi $65 \mathrm{~mm}$, sampah/kotoran yang ikut jatuh ke penampungan jagung dapat dikeluarkan dengan baik tanpa tersumbat. Hasil pipilan jagung menjadi lebih bersih.

\section{Posisi dan bentuk sieve}

Pemasangan sieve dalam posisi lurus tanpa kemiringan seperti pada Gambar 10 dapat membuang sampah dan kotoran dari kelobot dan pohon jagung. Namun banyak jagung yang terbuang dalam posisi ini. Padahal diharapkan jagung dapat tersaring ke bawah menuju area penampungan jagung.

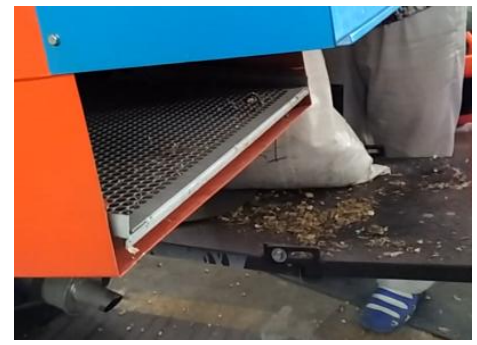

Gambar 10. Posisi sieve lurus 
Permasalahan kedua adalah sampah/kotoran dari bonggol jagung tidak tertiup angin dari blower di area ujung sieve seperti terlihat pada Gambar 11.

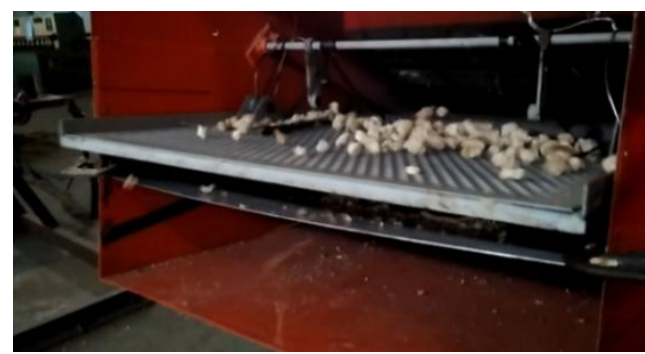

Gambar 11. Sampah/kotoran di ujung sieve

Jagung jatuh dari bagian thresher ke bagian sieve. Akibat dari putaran thresher, jagung yang jatuh ke sieve akan memantul ke arah luar sehingga banyak yang terbuang. Untuk mencegah terbuangnya jagung tersebut maka bentuk sieve tidak lurus. Sieve dibengkokkan dan diposisikan dengan kemiringan $20^{\circ}$. Selain itu, bagian atas diberi pelat penghalang agar jagung yang memantul dan bergerak ke arah luar tidak terbuang. Sampah yang menumpuk di ujung sieve terjadi karena posisi ujung sieve terlalu jauh dari blower sehingga tiupan blower tidak bisa membuang sampah. Hasil modifikasi terlihat pada Gambar 12 dan Gambar 13.

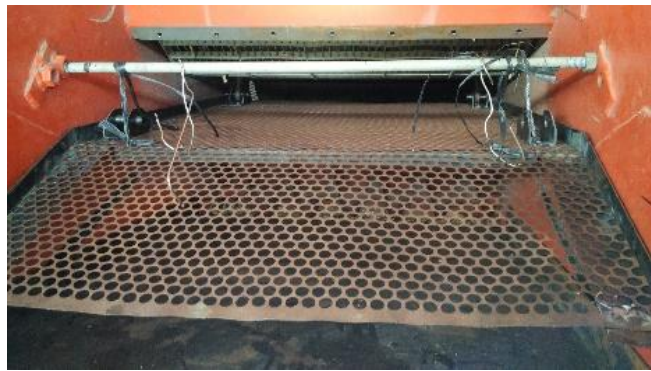

Gambar 12. Bentuk sieve hasil modifikasi

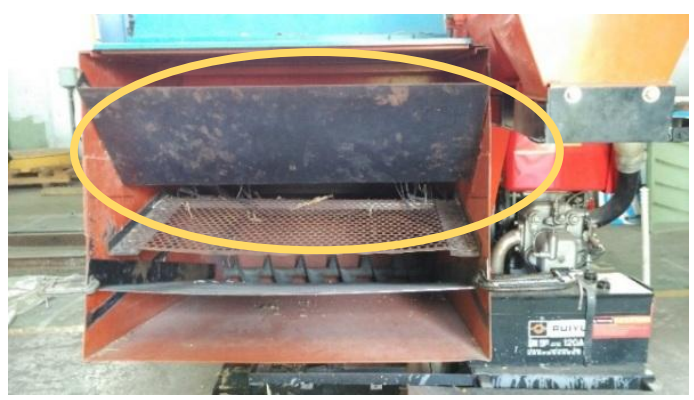

Gambar 13. Pelat penghalang

Dari hasil modifikasi tersebut, sampah/kotoran tidak menumpuk di ujung sieve karena adanya kemiringan di ujung sieve. Kemiringan tersebut berfungsi untuk mempermudah jatuhnya METAL INDONESIA Vol. 39 No. 1 Juni 2017 1-9) sampah/kotoran. Posisi sieve yang dipasang miring dan adanya pelat berfungsi untuk mengurangi terbuangnya jagung pipilan akibat tiupan blower dan putaran thresher. Hasil pengujian menunjukkan jagung pipilan yang bersih seperti pada Gambar 14 dan jagung yang terbuang sebanyak $6-7 \%$.

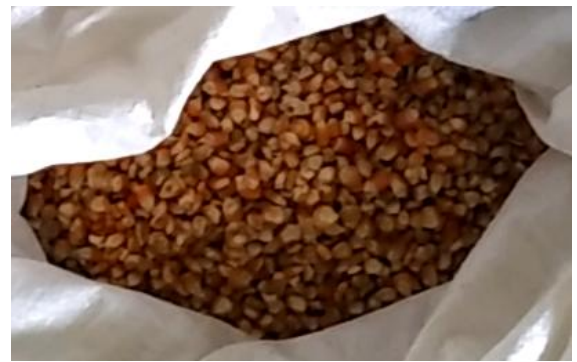

Gambar 14. Jagung pipilan hasil modifikasi sieve

\section{Putaran Engine dan Kecepatan Angin dari Blower}

Untuk mendapatkan parameter terbaik dalam pengoperasian mesin pemanen kombinasi maka dilakukan analisis putaran engine dan kecepatan angin dari blower. Tabel 2 menunjukkan pengaruh putaran engine dan kecepatan angin terhadap persentase jagung yang terbuang.

Tabel 2. Pengujian putaran engine dan kecepatan angin dari blower

\begin{tabular}{|c|c|c|c|c|c|}
\hline \multirow{2}{*}{ No } & \multirow{2}{*}{$\begin{array}{c}\text { Putara } \\
\text { n } \\
\text { Engine } \\
\text { (rpm) }\end{array}$} & \multicolumn{3}{|c|}{$\begin{array}{c}\text { Kecepatan angin } \\
(\mathrm{m} / \mathrm{s})\end{array}$} & \multirow{2}{*}{$\begin{array}{c}\% \\
\text { Jagung } \\
\text { terbuan } \\
\mathrm{g} \\
\end{array}$} \\
\hline & & $\begin{array}{c}\text { ata } \\
\mathrm{s}\end{array}$ & $\begin{array}{c}\text { tenga } \\
\mathrm{h}\end{array}$ & $\begin{array}{c}\text { bawa } \\
\mathrm{h}\end{array}$ & \\
\hline 1 & 1500,0 & 2,1 & 3,0 & 3,5 & 7,69 \\
\hline 2 & 1500,7 & 1,9 & 2,9 & 3,8 & 7,14 \\
\hline 3 & 1500,6 & 3,2 & 3,9 & 4,4 & 6,16 \\
\hline 4 & 1650,4 & 6,0 & 4,2 & 5,4 & 23,91 \\
\hline 5 & 1650,6 & 6,7 & 4,5 & 4,9 & 14,40 \\
\hline 6 & 1650,3 & 5,9 & 4,3 & 5,4 & 14,63 \\
\hline 7 & 1800,0 & 4,9 & 6,5 & 6,7 & 32,69 \\
\hline 8 & 1807,7 & 5,2 & 5,5 & 2,2 & 31,25 \\
\hline 9 & 1810,1 & 2,2 & 3,1 & 3,6 & 7,63 \\
\hline 10 & 1802,1 & 4,6 & 3,6 & 1,1 & 5,23 \\
\hline 11 & 1800,5 & 4,3 & 1,7 & 3,4 & 6,67 \\
\hline 12 & 1800,4 & 2,2 & 3,0 & 4,9 & 28,57 \\
\hline 13 & 1807,3 & 1,9 & 3,0 & 4,6 & 17,59 \\
\hline 14 & 1500,2 & 1,7 & 2,7 & 3,9 & 4,67 \\
\hline
\end{tabular}

Putaran engine berpengaruh terhadap kecepatan angin dari blower. Dari data di atas, 
pada putaran 1500 rpm kecepatan angin tidak terlalu besar sehingga jagung yang terbuang menjadi sedikit. Rata-rata jagung terbuang pada pengujian 1-3 adalah $7 \%$. Jika putaran engine diperbesar maka kecepatan angin pun semakin besar. Oleh karena itu, kecepatan angin perlu diturunkan dengan cara mengatur bukaan blower. Bukaan blower pada percobaan no.1-7 adalah $100 \%$ terbuka. Pada pengujian 8-14, bukaan blower diubah-ubah untuk mencari parameter terbaik. Kecepatan angin berpengaruh terhadap persentase jagung yang terbuang. Semakin tinggi kecepatan angin maka semakin besar pula persentase jagung yang terbuang. Pengaruh putaran engine, blower dan bukaan blower pada mesin pemanen kombinasi sesuai dengan hasil penelitian Mirzazadeh dkk mengenai faktor operasi yang berpengaruh terhadap performa mesin (Mirzazadeh, Abdollahpor, \& Vahed, 2015).

Hasil terbaik adalah pada pengujian 14 dengan kecepatan putaran engine 1500,2 rpm dan bukaan blower 50\% yang menghasilkan kecepatan angin rendah sehingga jagung yang terbuang sebesar 4,67\%. Hasil ini telah memenuhi syarat dari SNI 7428:2008 mengenai unjuk kerja standar efisiensi dengan jumlah jagung terbuang makimum 5\% (Badan Standardisasi Nasional 2008).

\section{KESIMPULAN}

Jagung yang dipanen menggunakan mesin pemanen kombinasi sebaiknya memiliki kadar air $<25 \%$ agar menghasilkan pipilan jagung yang bersih. Proses pembuangan kotoran memerlukan lubang pembuangan yang cukup besar agar tidak tersumbat. Dalam penelitian ini, celah $65 \mathrm{~mm}$ cukup untuk membuang sampah tanpa tersumbat. Area penampung jagung diberi kemiringan minimal $20^{\circ}$ agar jagung dapat bergerak ke area screw pembawa. Modifikasi sieve dan area penampung jagung telah berhasil memperbaiki performa sistem pembersih pada pemanen jagung kombinasi. Jagung pipilan yang dihasilkan sudah bersih dari kotorannya dan jagung yang terbuang menjadi lebih sedikit dari sebelumnya. Putaran engine dan kecepatan angin dari blower berpengaruh terhadap jagung yang terbuang saat proses penyaringan jagung. Berdasarkan hasil pengujian, putaran engine $1500 \mathrm{rpm}$ dengan bukaan blower 50\% menghasilkan kecepatan angin yang rendah sehingga jumlah jagung yang terbuang hanya $4,67 \%$. Modifikasi dan pengujian ini dilakukan di laboratorium dengan kondisi lantai yang rata dan datar. Oleh karena itu, mesin ini baik digunakan pada lahan jagung yang rata dan datar.

\section{SARAN}

Perlu dilakukan penelitian lebih lanjut untuk aplikasi mesin di lahan jagung yang sesungguhnya.

\section{UCAPAN TERIMA KASIH}

Penulis mengucapkan terima kasih kepada Ir. Eddy Siswanto, MAM sebagai Kepala Balai Besar Logam dan Mesin atas terselenggaranya penelitian ini. Terima kasih juga diucapkan kepada Koordinator Kegiatan, Peneliti, Perekayasa, dan Litkayasa yang terlibat dalam penelitian ini.

\section{DAFTAR PUSTAKA}

Badan Standardisasi Nasional. 2008. SNI 7428:2008 Mesin Pemipil Jagung - Unjuk Kerja Dan Cara Uji.

Darudkar, Anirudha G. 2015. "Literature Review of Corn Sheller Machine" 2 (01): 238-40.

Direktorat Pembinaan Sekolah Kejuruan Menengah Kementerian Pendidikan dan Kebudayaan RI. 2013. Ilmu Bahan Teknik Kelas X Semester 2.

Hibbeler, R.C. 2011. Mechanics of Materials. Pearson Prentice Hall. Vol. 8. doi:10.1017/CBO9781107415324.004.

Marques, Odair José, Pedro Soares, Vidigal Filho, Carlos Alberto Scapim, Deivid Lincoln Reche, Luiz Fernando Pricinotto, and Ricardo Shigueru Okumura. 2008. "Qualidade Comercial de Diferentes Híbridos de Milho Em Função Do Teor de Água Nos Grãos Durante a Colheita 1 Commercial Quality of Different Corn Hybrids as a Function of Grain Moisture Content during the Harvest," 911-20. doi:10.5433/1679-0359.2012v33n3p911.

Mirzazadeh, Ali. n.d. "Incorporating Skewness and Kurtosis in N Improvement of Combine Harve Harvester Cleaning Leaning System Performance" 3 (5): 1412-17.

Mohammad, Roohollah, Sanabadi Aziz, and Sherwin Amini. 2014. "Optimization of 
Combine Harvesting, Threshing, and Separating Systems for Reducing Corn Loss" 8 (10): 1715-25.

Pengfei, Zhao, Zhang Hanlin, Zhao Dongjie, Wang Zhijie, Fan Lifeng, Huang Lan, Ma

Qin, and Wang Zhongyi. 2015. "Rapid onLine Non-Destructive Detection of the Moisture Content of Corn Ear by Bioelectrical Impedance Spectroscopy." International Journal of Agricultural and Biological Engineering 8 (6): 37-45. doi:10.3965/j.ijabe.20150806.1238.

Peplinski, A J, R A Anderson, and O L Brekke. 1982. "Corn Dry Milling as Influenced by Harvest and Drying Conditions," 1114 17.

Setyaji, Muhammad Aziis Lyan. 2017. "Perencanaan Dan PEerhitungan Mesin Pemipil Jagung Dengan Kapasitas 300 $\mathrm{Kg} / \mathrm{jam} . ”$

Singh, Manjeet, S S Thakur, Rupinder Chandel, and Ankit Sharma. 2015. "Development and Field Evaluation of Corn - Stover Collector Attachment for Maize Combine Harvester." AGRICULTURAL

ENGINEERING TODAY 39(3): 3-9.

Voicu, Gheorghe, Tudor Casandroiu, and Constantin Tarcolea. 2008. "Testing Stochastic Models for Simulating the Seeds Separation Process on the Sieves of a Cleaning System, and a Comparison with Experimental Data." Agriculturae Conspectus Scientificus 73 (2): 95-101. 